\title{
Faecal calprotectin: A reliable diagnostic and prognostic biomarker in inflammatory bowel disease
}

\author{
Ripon Barua ${ }^{1}$, Najmun Nahar ${ }^{2}$, Jogendra Nath Sarker ${ }^{3}$, Sultana Razia ${ }^{4}$, Abu Naser Ibne Sattar ${ }^{4}$, Ahmed Abu Saleh ${ }^{4}$, Humayun Sattar $^{4}$ \\ ${ }^{1}$ Department of Microbiology, Shaheed Suhrawardy Medical College, Dhaka; ${ }^{2}$ Department of Microbiology, Sir Salimullah \\ Medical College, Mitford, Dhaka; ${ }^{3}$ Department of Microbiology, Dinajpur Medical College, Dinajpur; ${ }^{4}$ Department of \\ Microbiology \& Immunology, Bangabandhu Sheikh Mujib Medical University,
}

\begin{abstract}
Faecal calprotectin (FC) is supposed to be a reliable biomarker that quantifies intestinal inflammation in inflammatory bowel disease (IBD). This cross sectional study was aimed to determine the role of FC level in screening of suspected IBD patients and monitoring treatment response. This study was conducted by measurement of FC using a commercially available ELISA kit among 50 patients with chronic diarrhea who underwent colonoscopic evaluation (25 IBD cases, 10 other organic bowel diseases and 15 disease control) and 12 healthy control. IBD patients were followed up after one month of medical treatment. FC level showed significantly higher value $(p<0.001)$ among IBD patients $(496.7 \pm 127.15 \mu \mathrm{g} / \mathrm{g})$ than those in disease control $(82.17 \pm 75.64 \mu \mathrm{g} / \mathrm{g})$ and healthy control $(27 \pm 18.2 \mu \mathrm{g} / \mathrm{g})$. Measurement of FC in diagnosing IBD revealed the sensitivity $100 \%$, specificity $66 \%$, PPV $83 \%$ and NPV $100 \%$. The FC level decreased significantly $(\mathrm{p}<0.001)$ after one month of medical treatment of IBD patients $(90 \pm 43 \mu \mathrm{g} / \mathrm{g})$ from pre treatment value $(607.56 \pm 94 \mu \mathrm{g} / \mathrm{g})$. FC can be used as a reliable biomarker in screening of suspected IBD patients and to monitor treatment response.
\end{abstract}

Key words: Inflammatory bowel disease, Inflammation, Calprotectin.

\section{Introduction:}

Inflammatory bowel disease (IBD) is a chronic condition characterized by recurrent episodes of inflammation in the gastrointestinal tract and includes Crohn's disease (CD) and ulcerative colitis (UC) ${ }^{1}$. The patients with IBD require proper diagnosis and long-term monitoring of disease activity. Serological and hematological parameters like erythrocyte sedimentation rate (ESR), blood count, C-reactive protein (CRP) are used to assess intestinal inflammation but these have low sensitivity and specificity. Imaging studies such as CT and MRI scans, barium follow through and barium enemas can be useful but expensive and have suboptimal sensitivity and/or specificity and may expose the patient to ionizing radiation ${ }^{2}$. Endoscopy with biopsies is considered the gold standard for diagnosis of IBD and estimation of disease activity and efficacy of therapy ${ }^{3}$. But it is unsuitable

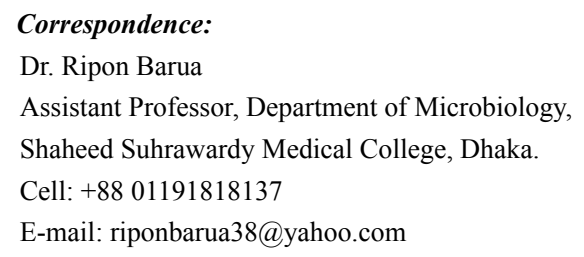

for frequent use as it is expensive and uncomfortable procedure with risk of various complications ${ }^{2,3}$. Non invasive, simple, sensitive, specific and harmless markers of intestinal inflammation have been looked for in recent years ${ }^{2}$.

Calprotectin, an break down product of leucocytes with the ability to bind with calcium and zinc with a molecular weight of $36.5 \mathrm{KDa}$ was identified as a good marker to assess intestinal inflammation in $\operatorname{IBD}^{3,4,5}$. It is derived predominantly from neutrophils and to a lesser extent, from monocytes and reactive macrophages ${ }^{6}$. It has both antimicrobial and anti proliferative properties and released extracellularly during neutrophil activation or during cell death and following endothelial adhesion of monocytes. As a result it can be detected and quantified in fluids with inflammation for example: serum, urine, cerebrospinal fluid and faeces ${ }^{7}$. It is resistant to heat and enzymatic degradation in the gut lumen and remains remarkably stable within faeces at room temperature for at least 7 days. Elevated faecal calprotectin (FC) level have been found in active IBD, intestinal neoplasm, intestinal polyp, intestinal tuberculosis, NSAID induced enteropathy, infective gastroenteritis etc and normal FC level is seen in healthy persons, patients with 
irritable bowel syndrome (IBS) and IBD in remission/ mucosal healing ${ }^{8,9,10}$. This protein can be quantified by enzyme-linked immunosorbent assay (ELISA) method ${ }^{3}$.

It has been shown that FC level correlates better with histological disease activity than macroscopic inflammation judged by clinicians at endoscopy. This biomarker can provide accurate non-invasive information regarding mucosal disease activity without necessarily the need for colonoscopy ${ }^{5}$. Different studies showed that FC is a specific, sensitive, non-invasive biomarker for gut inflammation ${ }^{11}$. Meta-analysis from Netherland reported a significant reduction of colonoscopy in adult and children because of introducing $\mathrm{FC}$ as screening marker ${ }^{12}$. FC has also proved to be a reliable marker in assessing treatment response of IBD patients ${ }^{13}$.

The present study was conducted to determine the role of FC level in screening of suspected IBD patients and monitoring treatment response among them.

\section{Materials and Methods:}

This cross sectional study was conducted in the department of Microbiology and Immunology of Bangabandhu Sheikh Mujib Medical University (BSMMU) during January 2011 to December 2011 and received prior approval from Ethical Review Committee of BSMMU and all participants gave informed written consent. All collected data were checked, edited and analyzed by using computer based SPSS software version 16.0. Data were presented by frequency distribution and percentage. The level of significance was calculated by t-test.

Fifty patients with chronic diarrhoea for ? 6 weeks with or without other gastrointestinal symptoms such as abdominal pain and vomiting, attending the department of Gastroenterology of BSMMU, Bangladesh Institute of Research and Rehabilitation in Diabetes, Endocrine and Metabolic Disorder (BIRDEM) and Dhaka Medical College Hospital (DMCH) were enrolled in this study. The patients below 2 years of age and with the history of gastrointestinal surgery in last 2 months, recent or current infective gastroenteritis, taking NSAID/Aspirin ( $>2$ tab/week), known immunodeficiency state or receiving chemotherapy or radiotherapy were excluded. All patients were evaluated by colonoscopy and biopsy materials were collected from the patients with abnormal colonoscopic findings while not from the patients with normal colonoscopic findings. They were followed up after one month of medical treatment. Clinical disease activity of symptomatic patients was determined as mild/moderate/severe by using Sutherland disease activity index and Harvey-Bradshaw disease activity index ${ }^{14} .12$ healthy persons having no gastrointestinal symptoms without colonoscopic evaluation were included as healthy control.

Stool samples were collected from all patients before bowel preparation for colonoscopy and from healthy control. All laboratory works were performed in the department of Microbiology and Immunology of BSMMU, Dhaka. Collected stool samples were stored at $-20^{\circ} \mathrm{C}$. Mean time difference between specimen collection and analysis of FC measurement was 3 months. Analysis was performed using CALPROTECTIN ELISA kit (BÜHLMANN AG Co., Switzerland) following the manufacturer's instructions. The FC level was calculated from the standard curve obtained with the kit standards and expressed as $\mu \mathrm{g} / \mathrm{g}$ of stool. Mean FC level was calculated among healthy control and disease control (mean $\pm 2 \mathrm{SD}$ ) and cut-off was set at $100 \mu \mathrm{g} / \mathrm{g}$.

\section{Results:}

Among 50 symptomatic patients, 25 (50\%) IBD cases and 10 (20\%) other organic bowel diseases (OBD) were detected while $15(30 \%)$ had normal colonoscopic findings (disease control group). Out of 25 IBD cases 21 (84\%) had UC and 4 $(16 \%)$ had CD. Among 10 other OBD cases, $6(60 \%)$ cases of colorectal carcinoma, $1(10 \%)$ case of intestinal tuberculosis and $3(30 \%)$ cases of intestinal polyp were detected. Mean age was 38 years (range, 7-59 years) among UC patients and 39 years (range, 19-55 years) among $C D$ patients. Male, female ratio was 2: 1 in UC patients and 1: 1 in CD patients. Among 25 IBD patients, only 10 were attended for follow up after one month of medical treatment. Rest 15 patients were lost to follow up.

In this study, FC level showed significantly higher value $(\mathrm{p}<0.001)$ among IBD patients $(496.7 \pm 127.15 \mu \mathrm{g} / \mathrm{g})$ than those in disease control $(82.17 \pm 75.64 \mu \mathrm{g} / \mathrm{g})$ and healthy control $(27 \pm 18.2 \mu \mathrm{g} / \mathrm{g})$. No significant difference in FC level between IBD and other OBD was observed $(\mathrm{p}>0.05)$ (TableI). Significantly higher level $(\mathrm{p}<0.001)$ of $\mathrm{FC}$ was noted among the IBD patients with severe disease activity $(559.1 \pm 87.74 \mu \mathrm{g} / \mathrm{g})$ than those with mild disease activity $(289.5 \pm 76.61 \mu \mathrm{g} / \mathrm{g})$ (Table-II). The FC level significantly $(\mathrm{p}<0.001)$ decreased after one month of medical treatment in follow up IBD patients $(90 \pm 43 \mu \mathrm{g} / \mathrm{g})$ from pre treatment value $(607.56 \pm 94 \mu \mathrm{g} / \mathrm{g})$ which correlated with the reduction of clinical disease activity from severe to mild (Table-III, TableIV). Measurement of FC in diagnosing IBD revealed the sensitivity $100 \%$, specificity $66 \%$, PPV $83 \%$ and NPV $100 \%$ considering $100 \mu \mathrm{g} / \mathrm{g}$ as cut-off value. 
Table-I: Faecal calprotectin level among the study population

\begin{tabular}{lcccc}
\hline $\begin{array}{l}\text { Faecal } \\
\text { calprotectin } \\
(\boldsymbol{\mu g} / \mathbf{g})\end{array}$ & $\begin{array}{c}\text { IBD } \\
(\mathbf{n}=\mathbf{2 5}) \\
(\mathbf{n}=\mathbf{1 0})\end{array}$ & $\begin{array}{c}\text { Other Organic } \\
\text { bowel diseases } \\
(\mathbf{n}=\mathbf{1 5})\end{array}$ & $\begin{array}{c}\text { Disease } \\
\text { control } \\
(\mathbf{n}=\mathbf{1 2})\end{array}$ & $\begin{array}{c}\text { Healthy } \\
\text { control }\end{array}$ \\
\hline mean \pm SD & $496.7 \pm 127.15$ & $421.75 \pm 140.5$ & $82.16 \pm 75.64$ & $27 \pm 18.2$ \\
range & $230.7-748.8$ & $217.3-743.8$ & $17.1-280.6$ & $9.25-74.8$ \\
p-value & & $p>0.05$ & $\mathrm{p}<0.001$ & $\mathrm{p}<0.001$ \\
\hline
\end{tabular}

Note: IBD: Inflammatory bowel disease.

Table-II: Faecal calprotectin level among IBD patients according to clinical disease activity

\begin{tabular}{lccc}
\hline Clinical disease activity & \multicolumn{2}{c}{ Faecal calprotectin $(\boldsymbol{\mu g} / \mathbf{g})$} & p-value \\
\cline { 2 - 3 } & mean \pm SD & range & \\
\hline Mild $(\mathrm{n}=4)$ & $289.5 \pm 76.61$ & $230.7-352.7$ & $\mathrm{p}>0.05$ \\
Moderate $(\mathrm{n}=5)$ & $462.9 \pm 69.09$ & $392.7-572.1$ & $\mathrm{p}>0.05$ \\
Severe $(\mathrm{n}=16)$ & $559.1 \pm 87.74$ & $443.8-748.8$ & $\mathrm{p}<0.001$ \\
\hline
\end{tabular}

Note: IBD: Inflammatory bowel disease.

Table-III: Faecal calprotectin level among IBD patients on diagnosis and follow up after one month of medical treatment

\begin{tabular}{cccccc}
\hline Serial number & \multicolumn{2}{c}{ On diagnosis } & & \multicolumn{2}{c}{ After one month of treatment } \\
\cline { 2 - 3 } & $\begin{array}{c}\text { Clinical } \\
\text { disease } \\
\text { activity }\end{array}$ & $\begin{array}{c}\text { Faecal } \\
\text { calprotectin } \\
(\boldsymbol{\mu g} / \mathbf{g})\end{array}$ & & $\begin{array}{c}\text { Clinical } \\
\text { disease } \\
\text { activity }\end{array}$ & $\begin{array}{c}\text { Faecal } \\
\text { calprotectin } \\
(\boldsymbol{\mu g} / \mathbf{g})\end{array}$ \\
\hline 1 & +++ & 523.60 & & + & 88.60 \\
2 & +++ & 481.30 & & + & 40.10 \\
3 & +++ & 652.60 & & + & 173.90 \\
4 & +++ & 579.0 & & + & 107.40 \\
5 & +++ & 748.40 & & + & 102.40 \\
6 & +++ & 580.40 & & + & 51.70 \\
7 & +++ & 726.50 & & + & 103.40 \\
8 & +++ & 568.30 & & + & 52.70 \\
9 & +++ & 392.70 & & +++ & 401.60 \\
10 & +++ & 445.20 & & +++ & 491.50 \\
\hline
\end{tabular}

Note: IBD: Inflammatory bowel disease, + : mild, +++: severe.

Table-IV: Mean faecal calprotectin among IBD patients on diagnosis and follow up after one month of treatment

\begin{tabular}{lccc}
\hline $\begin{array}{l}\text { Number of follow } \\
\text { up IBD patients }\end{array}$ & \multicolumn{2}{c}{ Faecal calprotectin $(\boldsymbol{\mu g} / \mathbf{g})$} & p- value \\
\hline & $\begin{array}{c}\text { On diagnosis } \\
\text { (mean } \pm \text { SD) }\end{array}$ & $\begin{array}{c}\text { After one month of } \\
\text { treatment } \\
(\text { mean } \pm \text { SD) }\end{array}$ & \\
\hline $\mathrm{n}=8$ & $607.56 \pm 94$ & $90 \pm 43$ & $\mathrm{p}<0.001$ \\
$\mathrm{n}=2$ & $419 \pm 37.12$ & $446.55 \pm 63.57$ & $\mathrm{p}>0.05$ \\
\hline
\end{tabular}

Note: IBD: Inflammatory bowel disease

\section{Discussion:}

An important step in the primary assessment of IBD patient is measurement of bowel inflammation as it defines the extent and severity of involvement at the beginning of treatment and during monitoring to target medical therapies and manage IBD related complications ${ }^{15}$. An inflammatory mediator directly released into the gut lumen from the inflammatory process might be an ideal test to detect bowel inflammation in $\mathrm{IBD}^{16}$. In recent studies, $\mathrm{FC}$ has been supposed to be a specific, sensitive, non-invasive, cheap and reliable marker for assessing intestinal inflammation ${ }^{17}$.The $\mathrm{FC}$ is stable in room temperature for at least 7 days makes it more suitable for routine clinical studies ${ }^{8}$.

In this study, FC levels in IBD cases were considerably higher $(\mathrm{p}<0.001)$ than those in disease control and healthy control. This finding confirms the results of previous studies $^{1,18}$. Raised FC level among the patients with other OBD (colorectal carcinoma, intestinal tuberculosis and intestinal polyp) were also detected in this study. There was no significant difference ( $p>0.05)$ of FC level between IBD and other OBD. Calprotectin is released from infiltrated inflammatory cells predominantly from neutrophils during the inflammatory response. So, FC can be used as a reliable marker to screen suspected patients with organic bowel diseases including IBD.

Significantly higher level $(\mathrm{p}<0.001)$ of FC was observed among IBD patients with severe disease activity than those with mild disease activity but no significant difference was observed regarding the duration of symptoms and age range. Significant reduction $(\mathrm{p}<0.001)$ of $\mathrm{FC}$ level after one month of medical treatment among IBD patients from pre treatment value were observed, which correlated with the reduction of clinical disease activity from severe to mild. Clinical improvement was not observed on 2 follow up IBD patients after one month of medical treatment rather a deterioration of symptoms and raised FC level were detected, which might be attributed to treatment failure, non compliance, associated other undetected organic bowel diseases like microscopic colitis during colonoscopic evaluation ${ }^{5}$.

This present study revealed $100 \%$ sensitivity for FC detection in IBD patients. $100 \%$ sensitivity and $95 \%$ specificity among the Italian population and $100 \%$ sensitivity and $92 \%$ specificity were reported among Egyptian population ${ }^{4,11}$. These studies are in agreement with this present study regarding sensitivity of FC. In this study, specificity of FC is low $(66 \%)$ in comparison with previous studies ${ }^{4,11}$, which might be due to lack of histopathological examination of biopsy materials from disease control group that could detect some organic bowel diseases in spite of normal colonoscopic findings. So, biopsy materials should be taken from all patients who underwent colonoscopic evaluation for proper diagnosis of bowel pathology. 
Various studies reported raised FC level among the patients with infective gastroenteritis ${ }^{8,9}$. But this faecal biomarker cannot distinguish infectious bowel diseases from organic bowel diseases. So, isolation and identification of infective pathogen or its marker should be done prior to colonoscopic examination where $\mathrm{FC}$ level is raised.

\section{Conclusion:}

In clinical practice, FC detection can be used as a reliable marker for quantifying intestinal mucosal inflammation and as a screening tool for selection of suspected IBD patients before colonoscopy in adjunct with other clinical and paraclinical examinations, to differentiate from non inflammatory bowel conditions like IBS. It can also be used to monitor treatment response in IBD patients as well as to adjust dose of medication and to detect treatment failure cases of IBD where FC level do not decline.

\section{Reference:}

1. Mehrjardi A, Saber AM, Mirskandari M et al. Comparison of Fecal Calprotectin Level in Inflammatory Bowel Disease and Irritable Bowel Syndrome. Govaresh 2010; 14 (4): 275-278.

2. Konikoff MR and Denson LA. Role of Fecal Calprotectin as a Biomarker of Intestinal Inflammation in Inflammatory Bowel Disease. Inflamm Bowel Dis 2006; 12 (6): 524-534.

3. Fagerberg UL, Lööf L, Lindholm J et al. Faecal Calprotectin: A Quantitative Marker of Colonic Inflammation in Children with Inflammatory Bowel Disease. J Pediatr Gastroenterol Nutr 2007; 45 (4): 414-420.

4. Saadany SE, Mohamed WF, Mohamed AA and Hammoudah SAF. Fecal Calprotectin as a Marker in Differentiating Irritable Bowel Syndrome from Organic Intestinal Disease. 2008. (Retrieved on 12.11.2010 from http:// elsadany66.wordpress.com)

5. Lamb CA and Mansfield JC. Measurement of faecal calprotectin and lactoferrin in inflammatory bowel disease. Frontl Gastroenterol 2010. (Retrieved on 24.11.2010 from www.fg.bmj.com)

6. Roseth AG, Fagerhol MK, Aadland E and Schjonsby H. Asssesment of the neutrophil dominating protein calprotectin in faeces. A methodological study. Scand $J$ Gastroenterol 1992; 27 (9): 793-798.

7. Baldassarre ME, Altomare MA, Fanelli M et al. Does calprotectin represent a regulatory factor in host defense or a drug target in inflammatory disease? Endocr Metab Immune Disord Drug Targets 2007; 7 (1): 1-5.
8. Sander J, Fagerhol MK, Bakken JS and Dale I. Plasma level of the leucocyte L1 protein in febrile conditions: relation to the aetiology, number of leucocytes in blood, blood sedimentation reaction and C-reactive protein. Scand J Clin Lab Invest 1984; 44 (4): 357-362.

9. Voganatsi A, Panyutich A, Miyasaki KT and Murthy RK. Mechanism of extracellular release of human neutrophil calprotectin complex. J Leukoc Biol 2001; 70 (1): 130-134.

10. Costa F, Mumola MG, Bellini M et al. Role of faecal calprotectin as non-invasive marker of intestinal inflammation. Digest Liv Dis 2003; 35 (9): 642-647.

11. Carroccio A, Lacono G, Cottone $M$ et al. Diagnostic Accuracy of Faecal Calprotectin Assay in Distinguishing Organic Causes of Chronic Diarrhea from Irritable Bowel Syndrome: A Prospective Study in Adults and Children. Clin chem 2003; 49 (6): 861-867.

12. van Rheenen PF, Van de Vijver E and Fidler V. Faecal calprotectin for screening of patients with suspected inflammatory bowel disease: diagnostic meta-analysis. $B M J$ 2010. (Retrieved on 15.01.2012 from http://www.bmj.com/ content/341/bmj.c33 69)

13. Sipponen T, Savilahti E, Kärkkäinen $\mathrm{P}$ et al. Fecal calprotectin, lactoferrin and endoscopic disease activity in monitoring anti-TNF-alpha therapy for Crohn's disease. Inflamm Bowel Dis 2008; 14 (10): 1392-1398.

14. Ouyang Q, Tandon R, Goh KL et al. Management consensus of inflammatory bowel disease for the AsiaPacific region. J Gastroenterol Hepatol 2006; 21 (12): 1772-1782.

15. Bamias G, Sugawara K, Pagnini C and Cominelli F. The Th 1 immune pathway as a therapeutic target in Crohn's disease. Curr Opin Investig Drugs 2003; 4 : 1279-1286.

16. Wassell J, Dolwani S, Metzner M, Losty H, Hawthorne A. Faecal calprotectin: a new marker for Crohn's disease? Ann Clin Biochem 2004; 41: 230 -232.

17. Sidler MA, Leach ST and S. Day AS. Fecal S100A12 and Fecal Calprotectin as noninvasive Markers for Inflammatory Bowel Disease in Children. Inflamm Bowel Dis 2008; 14: 359-366.

18. Tibble JA, Sigthorsson $\mathrm{G}$ and Foster $\mathrm{R}$ et al. Use of surrogate markers of inflammation and Rome criteria to distinguish organic from nonorganic intestinal disease. Gastroenterol 2002; 123 (2): 450-460. 